\title{
Editorial
}

Neuro

epidemiology

\section{Challenges of Epidemiological Research on Epilepsy in Resource-Poor Countries}

\author{
Fabrice Quet $^{\mathrm{a}} \quad$ Peter Odermatt $^{\mathrm{b}} \quad$ Pierre-Marie Preux $^{\mathrm{a}}$ \\ anstitute of Neuroepidemiology and Tropical Neurology (EA 3174), University of Limoges, Limoges, France; \\ ${ }^{b}$ Department of Public Health and Epidemiology, Swiss Tropical Institute, Basel, Switzerland
}

\section{Key Words}

Epilepsy · Epidemiology • Public health · Developing countries

Epilepsy is one of the most common neurological disorders. Today, an estimated 50 million people live with epilepsy (PWE), 80\% of whom reside in developing countries. The public health significance is particularly high in these settings because of its high prevalence, its seizure acuteness and frequency, and the sociological, psychosocial and financial consequences for the households it affects.

The difficulties encountered managing seizures and implementing epilepsy prevention and control programmes are numerous. The recently published Atlas of Epilepsy Care [1] describes the public health dimensions and highlights underlying global features. It shows that epilepsy is a disorder of internationally recognized importance in resource-poor countries; but substantial local obstacles hinder control, which often requires comprehensive investigations. Hence, there is a need to conduct epidemiological studies particularly in these settings.

Resource-poor countries share demographic, sociological and economic features. They are particularly marked by ethnic, linguistic and religious richness, and their populations are frequently threatened by political instability and economic uncertainties. As a consequence, the health systems are typically weak and lack efficiency in addressing health needs. The purpose of this text is to highlight some of the methodological challenges faced when conducting epidemiological research on epilepsy in resource-poor settings.

An acute resource constraint is a dominant underlying feature of health services in developing countries. The treatment gap is huge (reaching more than 90\%) in most places. As only a small fraction of PWE benefit from treatment, health services are of limited value to conduct epidemiological research on this condition. Typically, beneficiaries of treatment originate from urban areas and belong to the economically advantaged section of the population, which does not represent the majority in need. Therefore, community-based studies are inevitable to correctly assess the living conditions and needs of PWE.

However, community-based epidemiological studies are challenging. Exact and reliable census data are rarely available, and denominators needed to calculate population prevalence or incidence rates are often crude estimations because they are too resource-consuming to be determined properly. Door-to-door surveys produce an accurate account of denominators; however, migratory effects and other population dynamic elements cannot be easily captured by this technique.

Passive case finding of PWE underestimates the actual number. Those most affected often do not come forward. Stigma, misconceptions and beliefs attached to this condition influence the open presentation of affected individuals in public meetings. Hence, active case detection

\section{KARGER \\ Fax +4161306 1234 \\ E-Mail karger@karger.ch}

www.karger.com (c) 2008 S. Karger AG, Basel

0251-5350/08/0301-0003\$24.50/0

Accessible online at:

www.karger.com/ned
Prof. Pierre-Marie Preux

Institute of Neuroepidemiology and Tropical Neurology (EA 3174)

University of Limoges

2 , rue du Dr. Marcland, FR-87025 Limoges (France)

Tel. +33 5554358 20, Fax +335554358 21, E-Mail preux@unilim.fr 
is necessary. Door-to-door surveys in a delimited area are frequently conducted [2]. Normally, they are performed in 2 steps. In a first step, a screening questionnaire is used to identify suspected cases. Subsequently, a confirmatory examination is performed by a specialist, preferably a neurologist.

A number of rapid and low-cost screening tools have been developed $[3,4]$; some of which report a sensitivity and specificity of up to 79.3 and $92.9 \%$, respectively. In order to increase the validity, door-to-door survey approaches are complemented by key informant methods or information from other sources such as medical registries. By combining the information of several independent sources, a capture-recapture method can be used. Estimates applying this technique were shown to better appreciate the burden [5].

The diagnosis of epilepsy relies on reported rather than observed seizures. The questioning of the patient and his close relatives is of underlying importance. The sensitivity and specificity of particular questions depend on the social and cultural background of the investigated population. Local adaptation and validation of the research tools are thus required to capture the different types of seizure and to reach cross-culturally comparable results.

When comparing epilepsy studies over time, difficulties arise from changing definitions. A single (standardized) definition allows a valid comparison between studies across sites and continents [6]. In 1993, an international commission defined epilepsy as: the recurrence of at least 2 seizures, unprovoked by any immediately identified cause, occurring in more than $24 \mathrm{~h}$, precluding febrile seizures and neonatal seizures (in this definition, multiple seizures occurring in a 24-hour period and status epilepticus are considered as a single event) [7]. In 2005 , a new definition was put forward by the International League Against Epilepsy and the International Bureau for Epilepsy [8]: epilepsy is a disorder of the brain characterized by an enduring predisposition to generate epileptic seizures and by neurobiological, cognitive, psychological and social consequences of this condition. Although this definition takes into account some weaknesses of the earlier one, it poses a particular problem for epidemiological practice as it does not clearly spell out how 'enduring predisposition' should be measured. In the previous definition of epilepsy the predisposition was accounted for by the need of a second seizure episode $[9$, 10]. This broader and less operational definition of epilepsy is most likely to reduce the comparability of epilepsy studies. Recent reviews on epilepsy in Latin America [11], sub-Saharan Africa [12], Europe [13], North
America [14] and Asia [15] show the wealth of information which has been collected over the past decade. In the light of the changed definition, a critical revisiting of the comparable information will be required; particularly for resource-poor settings, where the burden of disease is highest.

Mortality data of PWE in developing countries are scarce. A recent effort in China to address this gap revealed that PWE had a 3-4 times higher mortality than the general population [16]. Most probably the epilepsyassociated mortality is also considerably elevated elsewhere. Accurate mortality information is essential to place epilepsy correctly within the burden of disease context. Prospective cohort studies are recommended to investigate this issue [17]. They rely in turn on a comprehensive demographic database updated over time. Sites with a continuous demographic surveillance system can provide this information. Another possibility is to integrate surveillance of epilepsy in cohort surveys in progress for other purposes. There is a need to follow up the possibilities to include epilepsy surveys during data collection rounds of such research platforms.

The World Health Report 2006 is dedicated to the actual chronic shortage of adequately trained staff at all levels of the health system [18]. This is of particular importance for developing counties and an acute issue in neurology i.e. in Africa, where the median number of neurologists is 0.3 per million people, and 11 countries do not have any [19]. This penury of qualified health staff has immediate implications. In most countries, it is difficult to find adequately trained researchers and assistants for field research activities. Application of screening tools, case ascertainment, classifications of seizures and case management are particularly dependent on qualified professionals. In addition, qualitative research techniques are essential in understanding the socio-cultural environment which PWE have to face. Aspects of perception of epilepsy, stigmatization or associated conditions (such as depression) need these additional research tools. Most frequently, these research competences are simply absent in developing nations. Hence, external personnel are essential to meet the demand, and training of local health staff is an integral part in research activities.

The classification of epileptic seizures depends on the availability of electroencephalography (EEG), which is a helpful tool for differentiation between generalized and focal seizures. Portable digital EEG devices, which can be brought to remote communities, are viable alternatives to health-facility-based investigations. The efforts to record EEG in field studies are sometimes excessive and costly 
when compared to the benefits: rarely seizure types need reclassification after EEG examination [20]. In the absence of EEG, emphasis must be placed on a comprehensive clinical assessment and follow-up. Consistently performed, it can provide fundamental information for seizure management options, e.g. diaries of PWE logging essential information, such as the moment and circumstances of seizures, provide useful information on the underlying causes and risk factors, as well as information on the consequences of seizures on the patient and family. A well-designed and followed-up diary, e.g. accompanied by in-depth interviews, therefore becomes a valuable research tool in most remote and underprivileged areas.

Patients diagnosed as having epilepsy in the course of the investigation must be provided with treatment. In case of epilepsy, this is a long-term commitment. A working approach combining research and intervention must be achieved. Such programs require an established partnership of research- and service-oriented institutions and solid financial assistance.

In the majority of the patients epilepsy is a controllable condition. In the essential drug lists of most countries cheap anti-epileptic drugs are included, but tremendous treatment gaps persist. The performance of the health system is challenged: quick solutions are unlikely to exist. Rather, there is a need for committed work to thoughtfully improve step by step the local health delivery system, supported by epidemiological evidence.

\section{References}

1 World Health Organization, International Bureau for Epilepsy, International League Against Epilepsy: Atlas - Epilepsy Care in the World 2005. Geneva, World Health Organization, 2005

2 Placencia M, Suarez J, Crespo F, Sander JW, Shorvon SD, Ellison RH, Cascante SM: A large-scale study of epilepsy in Ecuador: methodological aspects. Neuroepidemiology 1992;11:74-84.

3 Placencia M, Sander JW, Shorvon SD, Ellison RH, Cascante SM: Validation of a screening questionnaire for the detection of epileptic seizures in epidemiological studies. Brain 1992;115:783-794.

4 Preux PM: Questionnaire in a study of epilepsy in tropical countries. Bull Soc Pathol Exot 2000;93:276-278.

5 Debrock C, Preux PM, Houinato D, DruetCabanac M, Kassa F, Adjien C, Avode G, Denis F, Boutros-Toni F, Dumas M: Estimation of the prevalence of epilepsy in the Benin region of Zinvié using the capture-recapture method. Int J Epidemiol 2000;29:330-335.

6 Shorvon SD, Farmer PJ: Epilepsy in developing countries: a review of epidemiological, sociocultural, and treatment aspects. Epilepsia 1988;29:36-54.

7 Commission on Epidemiology and Prognosis, International League Against Epilepsy: Guidelines for epidemiologic studies on epilepsy. Epilepsia 1993;34:592-596.
8 Fisher RS, Van Emde Boas W, Blume W, Elger C, Genton P, Lee P, Engel J Jr: Epileptic seizures and epilepsy: definitions proposed by the International League Against Epilepsy (ILAE) and the International Bureau for Epilepsy (IBE). Epilepsia 2005;46:470-472.

9 Jallon P: A propos de la nouvelle définition de la crise et de l'épilepsie. Epilepsies 2005; 17:283-284.

10 Beghi E, Berg A, Carpio A, Forsgren L, Hesdorffer DC, Hauser WA, Malmgren K, Shinnar S, Temkin N, Thurman D, Tomson T: Comment on epileptic seizures and epilepsy: definitions proposed by the International League Against Epilepsy (ILAE) and the International Bureau for Epilepsy (IBE). Epilepsia 2005;46:1698-1699.

11 Burneo JG, Tellez-Zenteno J, Wiebe S: Understanding the burden of epilepsy in Latin America: a systematic review of its prevalence and incidence. Epilepsy Res 2005;66: 63-74.

12 Preux PM, Druet-Cabanac M: Epidemiology and aetiology of epilepsy in sub-Saharan Africa. Lancet Neurol 2005;4:21-31.

13 Forsgren L, Beghi E, Oun A, Sillanpaa M: The epidemiology of epilepsy in Europe - a systematic review. Eur J Neurol 2005;12: 245-253.
14 Theodore WH, Spencer SS, Wiebe S, Langfitt JT, Ali A, Shafer PO, Berg AT, Vickrey BG: Epilepsy in North America: a report prepared under the auspices of the global campaign against epilepsy, the International $\mathrm{Bu}$ reau for Epilepsy, the International League Against Epilepsy, and the World Health Organization. Epilepsia 2006;47:1700-1722.

15 Mac TL, Tran DS, Quet F, Odermatt P, Preux PM, Tan CT: Epilepsy in Asia: epidemiology, aetiology and clinical management. Lancet Neurol 2007;6:533-543.

16 Ding D, Hong Z, Wang WZ, Wu JZ, de Boer HM, Prilipko L, Sander JW: Assessing the disease burden due to epilepsy by disability adjusted life year in rural China. Epilepsia 2006;47:2032-2037.

17 Logroscino G, Hesdorffer DC: Methodologic Issues in studies of mortality following epilepsy: measures, types of studies, sources of cases, cohort effects, and competing risks. Epilepsia 2005;46:3-7.

18 World Health Organization: World Health Report 2006. Working Together for Health 2006. Geneva, World Health Organization, 2006.

19 Anonymous: Neurology in sub-Saharan Africa - WHO cares? Lancet Neurol 2006;5: 637.

20 Diagana $M$, Nsengiyumva G, Tuillas $M$, Druet-Cabanac M, Bouteille B, Preux PM, Tapie P: Electroencephalograms (EEG) in 250 patients with epilepsy in a cysticercosis endemic area in Burundi. Neurophysiol Clin 2005;35:1-10. 